\title{
Glutamate receptor, ionotropic, N-methyl D-aspartate-associated protein 1 promotes colorectal cancer cell proliferation and metastasis, and is negatively regulated by miR-296-3p
}

\author{
ZAIHUA YAN ${ }^{1,2^{*}}$, PEIDONG LI ${ }^{1,2^{*}}$, YUAN XUE $^{1,2^{*}}$, HONGPENG TIAN ${ }^{1,2}$, \\ TONG ZHOU ${ }^{1,2}$ and GUANGJUN ZHANG ${ }^{1,2}$ \\ ${ }^{1}$ Second Department of Gastrointestinal Surgery, Affiliated Hospital of North Sichuan Medical College; \\ ${ }^{2}$ Institute of Hepatobiliary, Pancreatic and Intestinal Disease, North Sichuan Medical College, \\ Nanchong, Sichuan 637000, P.R. China
}

Received October 13, 2020; Accepted July 12, 2021

DOI: $10.3892 / \mathrm{mmr} .2021 .12339$

\begin{abstract}
N-methyl D-aspartate receptors (NMDARs) are closely associated with the development, growth and metastasis of cancer. Glutamate receptor, ionotropic, N-methyl D-aspartate-associated protein 1 (GRINA) is a member of the of the NMDAR family, and its aberrant expression is associated with gastric cancer. However, the role of GRINA in colorectal cancer (CRC) is not completely understood. In the present study, expression profiles of GRINA in several CRC databases were obtained and further verified using clinical CRC samples. The effects of GRINA overexpression on CRC progression both in vivo and in vitro were assessed. Briefly, cell proliferation was detected using MTT assay, and cell migration and invasion ability were evaluated by wound healing and Transwell assay. In addition, the molecular mechanism underlying the upregulated expression of GRINA in CRC was investigated. The regulatory association between GRINA and miR-296-3p was detected by luciferase assay, reverse transcription-quantitative PCR and western blotting. The results demonstrated that GRINA expression levels were significantly increased in tumor samples compared with those in healthy samples, and upregulated expression of GRINA was associated with a less favorable prognostic outcome in patients with CRC. GRINA overexpression significantly increased
\end{abstract}

Correspondence to: Dr Tong Zhou or Dr Guangjun Zhang, Second Department of Gastrointestinal Surgery, Affiliated Hospital of North Sichuan Medical College, 63 Wenhua Road, Nanchong, Sichuan 637000, P.R. China

E-mail: zhoutong0088@163.com

E-mail: zhanggj1977@126.com

"Contributed equally

Key words: colorectal cancer, glutamate receptor, ionotropic, N-methyl D-aspartate-associated protein 1, microRNA-296-3p, apoptosis, migration, invasion
CRC cell proliferation, invasion and migration. Additionally, it was determined that GRINA was post-transcriptionally regulated by microRNA (miR)-296-3p. Together, the results of the present study suggested the potential importance of the miR-296-3p/GRINA axis and highlighted potential novel targets for the management of CRC.

\section{Introduction}

Colorectal cancer (CRC) is common type of cancer worldwide. Over the last few decades, there have been notable advances in the diagnosis and treatment of CRC $(1,2)$; however, In China, the incidence and mortality rates of CRC were 376 and 191 per 10,000, respectively, in 2015 and have been increasing gradually over the past decade (3). Therefore, there is an urgent need to discover new and effective molecular targets for improving the prognostic outcomes of patients with CRC.

GRINA is a member of the N-methyl D-aspartate receptor (NMDAR) family and is located on chromosome 8q24.3 (4). An increasing number of studies have reported the association between NMDAR expression and cancer development (5-7). NMDAR inhibition in small cell lung and breast cancer promotes cancer cell apoptosis $(5,6)$. In addition, NMDARs have been suggested as candidate therapeutic targets for the management of ovarian cancer (6). In gastric cancer (GC), GRINA expression is upregulated, which enhances GC progression and suppresses apoptosis (7). However, the role of GRINA in CRC is not completely understood.

The present study aimed to examine the expression levels of GRINA in CRC tissues and cells, and to determine its prognostic value in patients with CRC. Additionally, the effects of GRINA on CRC cell proliferation, invasion and migration, as well as the mechanism underlying GRINA upregulation in CRC were assessed.

\section{Materials and methods}

Patients and tissue samples. Between September 2008 and December 2009, CRC tissues and corresponding non-carcinoma samples (distance from tumor margin, $\geq 5 \mathrm{~cm}$ ) were 
collected from 167 patients with CRC receiving surgical resection at The Affiliated Hospital of North Sichuan Medical College (Nanchong, China). The age and sex distribution of patients with CRC are shown in Table SI. Among the 167 patients, six patients developed distant metastases and were excluded from the study, as such a small sample size was not significant. All enrolled patients had not received any adjuvant therapies prior to surgery. The tissues were immersed in liquid nitrogen immediately after resection and then stored at $-80^{\circ} \mathrm{C}$ until subsequent analysis. The present study was approved by the Medical Ethics Committee of North Sichuan Medical College [approval no. 2021ER(A)006]. All patients provided written informed consent for participation in the present study. To evaluate postoperative survival, all CRC cases were periodically followed up for 11-132 months. The detailed clinical characteristics of the enrolled patients are presented in Table SI.

Bioinformatic analysis. GRINA expression profiles in solid tumors were compared with matched non-carcinoma samples based on data obtained from The Cancer Genome Atlas (TCGA). In addition, the FireBrowse (firebrowse.org) portal in TCGA was used for selecting and analyzing data (8). The University of California Santa Cruz Xena browser (xenabrowser.net) was used to analyze GRINA mRNA expression and copy number alterations (CNAs) in the TCGA-derived primary CRC cases (9). For improved validation of the GRINA mRNA expression levels within CRC samples, GRINA was analyzed in Oncomine (oncomine.org), an online database that contains previously published and publicly available microarray data (10). To validate the survival analysis results, Kaplan-Meier curves of overall survival (OS) were obtained from The Human Protein Atlas database (THPA; proteinatlas. org) (11). TargetScan (targetscan.org/vert_71/), starBase (starbase.info/) and Pictar (pictar.mdc-berlin.de/) were used to predict the miRNA most likely to bind to the mRNA of GRINA.

Cell culture. The normal colonic epithelial cell line FHC, 293T cells and five human CRC cell lines (SW480, SW620, HT29, LoVo and HCT116) were purchased from American Type Culture Collection. The 293T and CRC cell lines were cultured in DMEM (Invitrogen; Thermo Fisher Scientific, Inc.) supplemented with 10\% FBS (Invitrogen; Thermo Fisher Scientific, Inc.). The FHC cell line was cultured in DMEM:F12 (Sigma-Aldrich; Merck KGaA; cat. no. D8437) supplemented with $10 \%$ FBS. All cells were maintained in a humidified incubator at $37^{\circ} \mathrm{C}$ with $5 \% \mathrm{CO}_{2}$. The vendors stated the identity of the cells had been confirmed using STR profiling and were free of mycoplasma contamination. The HT-29 cell line was also identified by STR profiling in our laboratory. STR markers were analyzed (Amelogenin, CSF1P0, D2S1338, D3S1358, D5S818, D7S820, D8S1179, D13S317, D16S539, D18S51, D19S433, D21S11, FGA, Penta D, Penta E, TH01, TPOX and vWA).

Immunohistochemical staining and evaluation. CRC tissue was collected from patients with CRC, fixed with $4 \%$ paraformaldehyde for $12 \mathrm{~h}$ at room temperature and embedded in paraffin. Paraffin-embedded CRC tissues were sectioned into $4-\mu \mathrm{m}$ thick slices. After baking at $60^{\circ} \mathrm{C}$ for $2 \mathrm{~h}$, the tissue sections were deparaffinized using dimethylbenzene and rehydrated using a descending alcohol gradient. The sections were incubated with $0.3 \%$ hydrogen peroxide at room temperature for $30 \mathrm{~min}$ and then blocked using 10\% BSA (Sangon Biotech Co., Ltd.) for $1 \mathrm{~h}$ at room temperature. Subsequently, the sections were incubated overnight at $4^{\circ} \mathrm{C}$ with a rabbit anti-GRINA antibody (1:50; cat. no. ab216953; Abcam), followed by incubation with an HRP-conjugated secondary antibody (1:100; goat Anti-Rabbit IgG H\&L; cat. no. ab205718; Abcam) at $37^{\circ} \mathrm{C}$ for $2 \mathrm{~h}$. To develop signals, the tissues were stained with DAB (OriGene Technologies, Inc.) at room temperature for $1 \mathrm{~h}$. For counterstaining, tissues were stained with hematoxylin for $1 \mathrm{~min}$ at room temperature. All sections were dehydrated and sealed. Stained tissues were observed and imaged using a light microscope (Carl Zeiss AG). Sections labeled with rabbit IgG (cat. no. \#A7016; Beyotime Institute of Biotechnology) as the primary antibody were used as negative controls and known GRINA positive slides were used as positive controls. Scoring was performed based on the ratio of positively stained cells $(0,0-5 \% ; 1,6-35 \% ; 2,36-70 \%$; and $3,>70 \%)$ and the staining intensity ( 0 , no staining; 1 , weakly stained; 2 , moderately stained; and 3, strongly stained), as previously described (12). The final score was determined by multiplying the score of the percentage of the positive cells by the score of the staining intensity, and final scores were defined as follows:,$- 0-1 ;+, 2-3$; ,$++ 4-6$; and,$+++>6$. Low expression was defined as a total score $<4$, whereas high expression was defined as a total score $\geq 4$. The tissues were scored by two experienced pathologists independently.

Oligonucleotides and plasmid transfection. MicroRNA (miR/miRNA)-296-3p mimics (5'-GAGGGUUGGGUGGAG GCUCUCC-3'), miR-296-3p inhibitor (anti-miR-296-3p; 5'-GGAGAGCCUCCACCCAACCCUC-3'), miR-negative control (NC) mimics (5'-UUCUCCGAACGUGUCACGU-3') and anti-miR-NC (5'-UUUGUACUACACAAAAGUACUG-3') were provided by Guangzhou RiboBio Co., Ltd. The open reading frame of GRINA was amplified by PCR using primers containing KpnI and EcoRI restriction sites and subcloned into vector pcDNA 3.1(+) (BioVector NTCC, Inc.) to generate the construct pcDNA-GRINA with no 3'-UTR. The empty vector (NC plasmid) served as a negative control. The primers used were as follows: Forward, 5'-GGATCCGCCACCATGTCC CATGAAAAGAGTTTTTTG -3' and reverse, 5'-CACAAC TCGAGCTACTCCTTGGCGCGGCCAATGAT-3'. Cell transfections were performed using Lipofectamine ${ }^{\circledR} 2000$ reagent (Invitrogen; Thermo Fisher Scientific, Inc.) according to the manufacturer's protocol. In brief, $2 \times 10^{5}$ LoVo cells were cultured in 6-well plates at $37^{\circ} \mathrm{C}$ until they reached $60-70 \%$ confluence. Then $\sim 5 \mu \mathrm{g}$ corresponding transfectant (miR-296-3p or miR-NC mimics, pcDNA3.1-GRINA or pcDNA3.1-NC plasmid) was added. Cells were collected for subsequent experiments following $24 \mathrm{~h}$ co-culture at $37^{\circ} \mathrm{C}$.

Reverse transcription-quantitative (RT-q)PCR. Total RNA (including miRNA) was isolated from cells (SW480 or LoVo) and tissues using TRIzol ${ }^{\circledR}$ (Invitrogen; Thermo Fisher Scientific, Inc.) according to the manufacturer's protocol. To reverse transcribe miRNA to cDNA, the TaqMan miRNA 
Reverse Transcription kit (Applied Biosystems; Thermo Fisher Scientific, Inc.) with miR-296-3p specific primers (Applied Biosystems; Thermo Fisher Scientific, Inc.) was used according to the manufacturer's protocol. To determine the expression levels of mature miR-296-3p, qPCR was performed using TaqMan miRNA assays (Applied Biosystems; Thermo Fisher Scientific, Inc.). To reverse transcribe mRNAs to cDNA, the PrimeScript RT Reagent kit (Takara Bio, Inc.) was used according to the manufacturer's protocol. To determine GRINA mRNA expression levels, qPCR was performed using SYBR Premix Ex Taq II (Takara Bio, Inc.) and an ABI 7500 Real-Time PCR system (Applied Biosystems; Thermo Fisher Scientific, Inc.). The following thermocycling conditions were used for qPCR: $95^{\circ} \mathrm{C}$ for $10 \mathrm{~min}$; followed by 40 cycles of $95^{\circ} \mathrm{C}$ for $30 \mathrm{sec}, 60^{\circ} \mathrm{C}$ for $30 \mathrm{sec}$ and $72^{\circ} \mathrm{C}$ for $30 \mathrm{sec}$ and final extension at $72^{\circ} \mathrm{C}$ for $2 \mathrm{~min}$. Samples without cDNA template were used as the NCs. The sequences of the primers used for qPCR were as follows: miR-296-3p forward, 5'-ACTTTGGGTGGA GGCTCTCC-3' and reverse, 5'-CTGGTGTCGTGGAGTCGG CAATT-3'; U6 forward, 5'-CTCGCTTCGGCAGCACA-3' and reverse, 5'-AACGCTTCACGAATTTGCGT-3'; GRINA forward, 5'-GGATGATCGCCAGCTTCTAC-3' and reverse, 5'-GCGAAGATGAAGAGCACCAC-3'; $\beta$-actin forward, 5'-CCAAGGCCAACCGCGAGAAGATGAC-3' and reverse, 5'-AGGGTACATGGTGGTGCCGCCAGAC-3'. miRNA and mRNA relative expression levels were calculated using the $2^{-\triangle \triangle C q}$ method (13) and normalized to the internal reference genes U6 and GAPDH, respectively.

Lentivirus constructs. The plasmid (pLX304-Blast-V5) containing GRINA-HA and the NC plasmid were provided by Asia-Vector Biotechnology (Shanghai) Co., Ltd. The shRNA-containing plasmids (pGIZP-gfp-puro) and NC plasmid were purchased from Shanghai GenePharma Co., Ltd. The sequences of the short hairpin RNAs (shRNAs) are presented in Table SII. To generate stable cell lines, the pPACKH1 HIV Lentivector Packaging kit (System Biosciences, LLC) was used according to the manufacturer's instructions. Briefly, $1.0 \mu \mathrm{g}$ GRINA-HA- or shRNA-containing plasmids (corresponding control plasmid) and $5.0 \mu \mathrm{g}$ pPACKH1 (3rd generation packaging system) packaging plasmid mix (pPACKH1-GAG, pPACKH1-REV and pVSV-G plasmids) were transfected into 293T cells. After $24 \mathrm{~h}$, the collected culture media was mixed with PEG-it Reagent (System Biosciences) and incubated overnight at $4^{\circ} \mathrm{C}$ to concentrate the viruses. The culture medium containing virions was centrifuged at $72,000 \mathrm{x}$ g for $120 \mathrm{~min}$ at $4^{\circ} \mathrm{C}$. The centrifuged pellet was resuspended in $1 \mathrm{X}$ phosphate-buffered saline and aliquots were stored at $-80^{\circ} \mathrm{C}$. The viruses were transduced into SW480 or LoVo cells using polybrene ( $8 \mathrm{mg} / \mathrm{ml}$; Sigma-Aldrich; Merck KGaA) at MOI=20. After $24 \mathrm{~h}$, the medium containing virus were replaced with fresh complete medium. Stably transfected SW480 or LoVo cells were selected by adding puromycin $(6 \mu \mathrm{g} / \mathrm{ml})$ in medium and the maintenance concentration of puromycin in transfected cells was $3 \mu \mathrm{g} / \mathrm{ml}$. Successful transfection was confirmed using RT-qPCR and western blotting.

Cell proliferation analysis. MTT cell proliferation assays were performed to assess cell proliferation. Briefly, $100 \mu \mathrm{l}$ transfected cells (SW480 or LoVo; $5 \times 10^{3}$ cells/well) were plated in 96-well plates. After incubation for $24,48,72$ or $96 \mathrm{~h}$, $5 \mathrm{mg} / \mathrm{ml}$ MTT solution $(20 \mu \mathrm{l})$ was added to each well and incubated for a further $4 \mathrm{~h}$. Subsequently, the MTT solution was removed and $150 \mu \mathrm{l}$ DMSO was added. Absorbance was measured at a wavelength of $490 \mathrm{~nm}$ using a SpectraMax M5 microplate reader (Molecular Devices LLC). The experiment was performed in quintuplicate and repeated twice.

Wound healing assay. Transfected cells (SW480 or LoVo) were plated into 6-well plates and cultured at $37^{\circ} \mathrm{C}$ in DMEM containing 1\% FBS until they reached $100 \%$ confluency. Subsequently, a pipette tip was used to scrape the cell monolayer to generate a linear cell wound, and floating cells were gently washed twice with DMEM. Cells were cultured at $37^{\circ} \mathrm{C}$ in DMEM ( $\left.1 \% \mathrm{FBS}\right)$ for $24 \mathrm{~h}$. The cells migrating into the wounded areas were observed using a light microscope (magnification, $\mathrm{x} 20$ ) at 0 and $24 \mathrm{~h}$. Wound healing was assessed using MShot Image Analysis system 1.3.10 (Guangzhou Mingmei PhotoelectricTechnology Co, Ltd.). Each experiment was repeated three times.

Matrigel invasion assays. Transwell inserts (pore size, $8 \mu \mathrm{m}$; Corning, Inc.) were coated with Matrigel (BD Biosciences) for $30 \mathrm{~min}$ at $37^{\circ} \mathrm{C}$. Subsequently, transfected cells (SW480 or LoVo) $\left(1 \times 10^{5}\right.$ cells/well) in serum-free medium were plated into the upper chamber of the Transwell inserts in a 24-well plate. The lower chamber was filled with medium supplemented with $10 \%$ FBS. Following incubation for $24 \mathrm{~h}$ at $37^{\circ} \mathrm{C}$, cells in the lower chamber were fixed in $10 \%$ formalin at $25^{\circ} \mathrm{C}$ for $10 \mathrm{~min}$ and stained with $0.1 \%$ crystal violet at $25^{\circ} \mathrm{C}$ for 5 min and counted using an inverted light microscope (magnification, x20; Olympus Corporation). All experiments were repeated three times.

In vivo xenograft experiments. A total of 18 female BALB/C nude mice (age, 4 weeks; weight, $\sim 20 \mathrm{~g}$ ) were provided by Shanghai SLAC Laboratory Animal Co., Ltd. Animals maintained under standard animal housing conditions $\left(24^{\circ} \mathrm{C}\right.$, $60 \%$ humidity, 12-h light/dark cycle, free access to food and purified water) and were randomly assigned to one of two groups ( $\mathrm{n}=4$ per group; shGRINA and sh-NC group). The animal experiments were approved by the Experimental Animal Ethics Committee of North Sichuan Medical College (approval no. 20190907). The nude mice were subcutaneously injected with shGRINA or shNC-transfected LoVo cell suspension $\left(1 \times 10^{6} \mathrm{cells} / \mathrm{ml}\right)$ in $200 \mu 1$ serum-free medium through the lower back. After 4 weeks, all animals were sacrificed, the tumors were resected and tumor weight was measured. Mice were euthanized by the intraperitoneal injection of sodium pentobarbital $(200 \mathrm{mg} / \mathrm{kg})$. Tumor volume was determined as follows: Volume $\left(\mathrm{cm}^{3}\right)=$ length $\mathrm{x}$ width $/ 2$, where both length and width were measured in $\mathrm{cm}$. The maximum tumor diameter was $1.3 \mathrm{~cm}$ and the maximum tumor volume was $1.2 \mathrm{~cm}^{3}$. For tail vein metastasis, nude mice ( $\mathrm{n}=5$ per group) were injected with sh-GRINA- or sh-Ctrl-transfected LoVo cells $\left(2 \times 10^{6}\right)$ through the tail vein. After 8 weeks, the animals were sacrificed and the lung tissues were removed. Following paraffin embedding, pathological examination was performed. A dissection microscope was used to count the tumor metastases in the lungs (magnification, $\mathrm{x} 20$ ). 
Luciferase reporter assay. In the luciferase reporter assays, the mutant-type (MUT) or wild-type (WT) 3'-untranslated region (3'-UTR) of GRINA was subcloned into the empty psicheck-2 vector (Promega Corporation) at the XhoI-NotI restriction sites to produce the psicheck-2-GRINA-3'-UTR MUT and WT plasmids, respectively. Specific fragments were amplified from human genomic DNA extracted from nucleated cells using a genomic DNA extraction kit (ab156900; Abcam). The primers used were GRINA-WT forward, 5'-CACAACTCAGCTCGCTGTGCCCGCTCA GGT-3' and reverse, 5'-CACAACACAATCACTGACAAC AACCCCATT-3'; GRINA-MUT forward, 5'-AGGATCGGA CTCTCGTTGGGACCTGTATGTACACTGCAGA-3' and reverse, 5'- ACAGGTCCCAACGAGAGTCCGATCCTTTTC CCTAGGCTGT-3'. PCR was performed using Takara LA Taq polymerase and PCR system (Takara Biotechnology Co., Ltd.). The thermocycling conditions were as follows: Initial denaturation at $94^{\circ} \mathrm{C}$ for $5 \mathrm{~min}$; followed by 35 cycles of $94^{\circ} \mathrm{C}$ for $30 \mathrm{sec}, 60^{\circ} \mathrm{C}$ for $30 \mathrm{sec}$ and $72^{\circ} \mathrm{C}$ for $40 \mathrm{sec}$ and final extension at $72^{\circ} \mathrm{C}$ for $5 \mathrm{~min}$. To perform the luciferase reporter assays, $293 \mathrm{~T}$ cells $\left(1 \times 10^{5}\right.$ cells/well) were plated into a 24 -well plate. Subsequently, 293T cells were co-transfected with 2 ng pRL-TK (Promega Corporation), 200 ng psicheck-2-GRINA-WT or psicheck-2-GRINA-MUT and 40 nM miR-NC/miR-296-3p or anti-miR-NC/anti-miR-296-3p using Lipofectamine ${ }^{\circledR}$ 2000. Then, cells were transfected at $37^{\circ} \mathrm{C}$ for $48 \mathrm{~h}$. At $48 \mathrm{~h}$ post-transfection, cells were collected and luciferase activities were measured using the Dual-Luciferase Reporter assay system (Promega Corporation) according to the manufacturer's protocol. Firefly luciferase activities were normalized to Renilla luciferase activities.

Western blotting. Total protein was extracted from cells (transfected SW480 or LoVo) using RIPA lysis buffer (Beijing Solarbio Science \& Technology Co., Ltd.) containing proteinase inhibitors. Protein concentrations were determined using the BCA method. Proteins (50 $\mu \mathrm{g} / \mathrm{lane})$ were separated via $10 \%$ SDS-PAGE and transferred onto PVDF membranes. Following blocking with $5 \%$ skimmed milk for $1.5 \mathrm{~h}$ at room temperature, the membranes were incubated overnight at $4^{\circ} \mathrm{C}$ with primary antibodies targeted against: GRINA (rabbit; 1:1,000; cat. no. AP13558c; Abgent, Inc.) or GAPDH (mouse; 1:1,000; cat. no. AM1020b; Abgent, Inc.). Subsequently, the membranes were incubated with horseradish peroxidase-conjugated anti-rabbit (1:5,000; cat. no. sc-2357; Santa Cruz Biotechnology, Inc.) and anti-mouse (1:10,000; cat. no. Sc-2005; Santa Cruz Biotechnology, Inc.) secondary antibodies for $1 \mathrm{~h}$ at $37^{\circ} \mathrm{C}$. Protein bands were visualized using ECL (EMD Millipore). Protein expression was semi-quantified using ImageJ software (version 1.8.0; National Institutes of Health) with GAPDH as the loading control.

Statistical analysis. Continuous variables are presented as the mean \pm SD. The $\chi^{2}$ test was used to examine the association between GRINA expression levels and the clinicopathological features of patients with CRC. Comparisons between two groups were analyzed using the Student's t-test or Mann-Whitney $\mathrm{U}$ test. Comparisons among multiple groups were analyzed using one-way ANOVA followed by Dunnett's or Tukey's post hoc test. The Kaplan-Meier method was used to analyze survival following surgery and a log-rank test was used for comparison of survival. Spearman's correlation analysis was used to determine the correlation between miR-296-3p and GRINA expression in CRC samples. Statistical analyses were performed using SPSS software (version 19; IBM Corp.). R (version 3.5.2: r-project.org/) and GraphPad Prism (version 6; GraphPad Software, Inc.) were used to prepare the graphs. $\mathrm{P}<0.05$ was considered to indicate a statistically significant difference.

\section{Results}

GRIN expression is significantly upregulated in CRC tissues compared with healthy tissues. The differential expression of GRINA at the mRNA level was detected by comparing cancer samples with healthy samples in FireBrowse. GRINA expression was upregulated by $\sim 3 \mathrm{x}$ in CRC samples compared with the corresponding healthy samples (Fig. 1).

In samples obtained from TCGA and Oncomine, GRINA mRNA expression was significantly increased in CRC samples compared with healthy samples (Fig. 2A and B). Additionally, it was shown that the amplification was associated with higher mRNA expression levels of GRINA (Fig. 2A).

To validate the results of the bioinformatics analysis, 161 pairs of freshly resected CRC and healthy samples were obtained to assess the GRINA mRNA and protein expression levels. GRINA expression levels in the tumor samples were higher compared with the healthy samples (Fig. 2C and D), which was consistent with the bioinformatics analysis.

The correlation between the OS of patients and GRINA expression was examined using the Kaplan-Meier method. A total of 161 patients with CRC were categorized into high or low groups based on the median mRNA expression level of GRINA. The median GRINA mRNA expression level was 14.352 (4.256-23.364). Kaplan-Meier survival analysis demonstrated that GRINA mRNA expression was significantly associated with the OS of patients with CRC. Specifically, upregulated expression of GRINA was associated with a worse OS (Fig. 2F). This result was confirmed using the Kaplan-Meier survival analysis on the data obtained from THPA (Fig. 2E).

Association between GRINA expression and the clinicopathological factors of patients with CRC. To determine the value of GRINA in clinical and pathological diagnosis, immunohistochemical staining of the 161 CRC samples was performed. The association between GRINA expression and the clinicopathological characteristics of the patients is presented in Table I. GRINA expression was significantly associated with age $(\mathrm{P}=0.045)$, American Joint Committee on Cancer stage $(\mathrm{P}=0.011)$ and lymphatic invasion $(\mathrm{P}=0.0001)$, but not sex, $\mathrm{T}$ stage, differentiation or tumor location.

GRINA promotes CRC cell proliferation, migration and invasion in vitro. RT-qPCR was performed to examine the mRNA expression levels of GRINA in the normal colonic FHC cell line and the five CRC cell lines (HT29, HCT116, LoVo, SW480 and SW620). GRINA expression was significantly higher in the five CRC cell lines compared with that in FHC cells (Fig. 3A). Among the five CRC cell lines, GRINA expression was notably higher in LoVo and SW620 


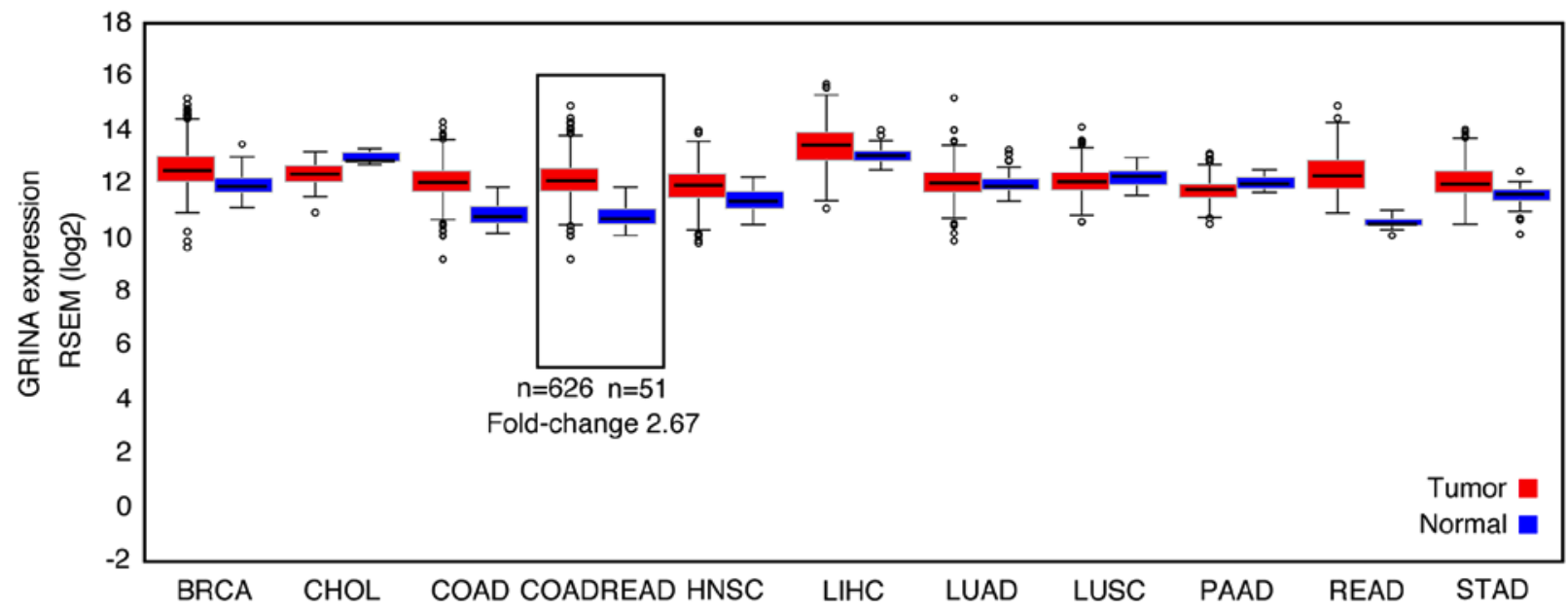

Figure 1. GRINA mRNA expression levels in a range of solid tumor samples and matched non-carcinoma samples based on bioinformatics analysis. GRINA, glutamate receptor, ionotropic, N-methyl D-aspartate-associated protein 1; RSEM, RNA-Seq by Expectation-Maximization; BRCA, breast invasive carcinoma; CHOL, cholangiocarcinoma; COAD, colon adenocarcinoma; COADREAD, colon adenocarcinoma/rectum adenocarcinoma; HNSC, head and neck squamous cell carcinoma; LIHC, liver hepatocellular carcinoma; LUAD, lung adenocarcinoma; LUSC, lung squamous cell carcinoma; PAAD, pancreatic adenocarcinoma; READ, rectum adenocarcinoma; STAD, stomach adenocarcinoma.

cells compared with that in HT29, HCT116 and SW480 cells (Fig. 3A). Therefore, SW480 and LoVo cells were used for subsequent in vitro experiments. Lentiviral transfection was performed to overexpress GRINA expression in SW480 cells and knock down GRINA expression in LoVo cells. RT-qPCR and western blotting were performed to verify successful GRINA overexpression and knockdown (Fig. 3B and C).

MTT, wound healing and Matrigel invasion assays were performed to assess the effect of GRINA on CRC cell proliferation, migration and invasion, respectively. The results suggested that GRINA overexpression significantly increased SW480 cell proliferation, migration and invasion compared with the NC group (Fig. 3D, F and H). Conversely, GRINA knockdown significantly suppressed LoVo cell growth, migration and invasion compared with the shNC group (Fig. 3E, G and I). Thus, the results indicated that GRINA served a tumor-promoting effect on CRC cells.

GRINA promotes LoVo cell growth and metastasis in vivo. To determine the effect of GRINA on tumor growth in vivo, a BALB/C xenograft nude mouse model was used, in which mice were transplanted with shGRINA- or shNC-transfected LoVo cells. After 4 weeks, the shGRINA group presented with significantly smaller and lighter tumors compared with those obtained from mice in the shNC group (Fig. 4A-C). To assess metastasis, the shNC- and shGRINA-transfected LoVo cells were injected into nude mice via the tail vein. At 8 weeks post-injection, the number of metastatic lesions in the lungs was counted. As shown in Fig. 4D, the shNC group displayed a larger metastatic lesions in the lung compared with the small lesions observed in the shGRINA group. In addition, the shGRINA group displayed significantly fewer metastatic lesions compared with the shNC group (Fig. 4E). These results were consistent with the in vitro results, further confirming the role of GRINA in the development of CRC.

miR-296-3p directly targets GRINA in CRC cells. The roles of various miRNAs as vital regulatory factors in the development and progression of CRC have previously been identified (14). However, their specific roles in the regulation of CRC invasion and metastasis are not completely understood. Previous studies have demonstrated that miR-296 inhibits CRC progression by targeting different genes $(15,16)$. Several online tools, including TargetScan, starBase and Pictar, were used in the present study to predict the miRNA most likely to bind to the mRNA of GRINA. The results suggested the direct binding of miR-296-3p to the 133-139 position in the 3'-UTR of GRINA mRNA (Fig. 5A). Interestingly, GRINA mRNA expression was negatively correlated with miR-296-3p expression (Fig. 5B). The binding between GRINA and miR-296-3p was confirmed using a dual luciferase reporter assay. The WT or MUT 3'-UTR GRINA luciferase reporter gene was co-transfected into $293 \mathrm{~T}$ cells with miR-296-3p mimics, miR-NC, anti-miR-296-3p or anti-miR-NC. Compared with the miR-NC and anti-miR-NC groups, respectively, miR-296-3p overexpression significantly reduced luciferase activity, whereas miR-296-3p knockdown significantly increased the luciferase activity of the WT 3'UTR (Fig. 5C and D). Moreover, the functions of miR-296-3p mimics and anti-miR-296-3p were abolished by co-transfection with the MUT 3'-UTR (Fig. 5C and D), further confirming binding between miR-296-3p and GRINA mRNA. miR-296-3p inhibitor or mimics were transiently transfected into cells to regulate miR-296-3p expression levels. RT-qPCR was performed to confirm successful transfection (Fig. 5E and F). Compared with the anti-miR-NC and miR-NC groups, respectively, miR-296-3p knockdown upregulated GRINA mRNA and protein expression in SW480 cells, whereas miR-296-3p overexpression decreased GRINA expression in LoVo cells (Fig. 5G and H). Collectively, these results suggested that miR-296-3p regulated GRINA expression through direct interaction with the 3'-UTR in CRC.

miR-296-3p suppresses CRC cell proliferation and invasion via GRINA. To further investigate the roles of GRINA and 
A

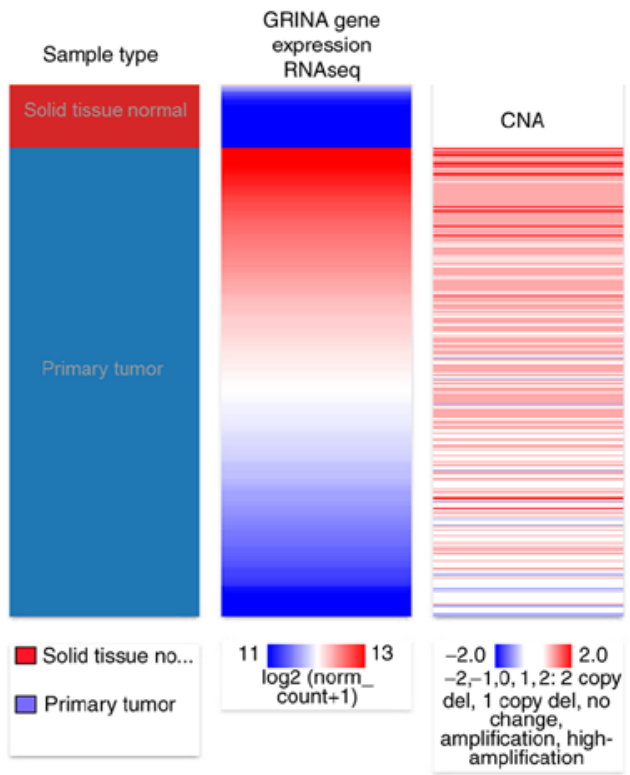

C

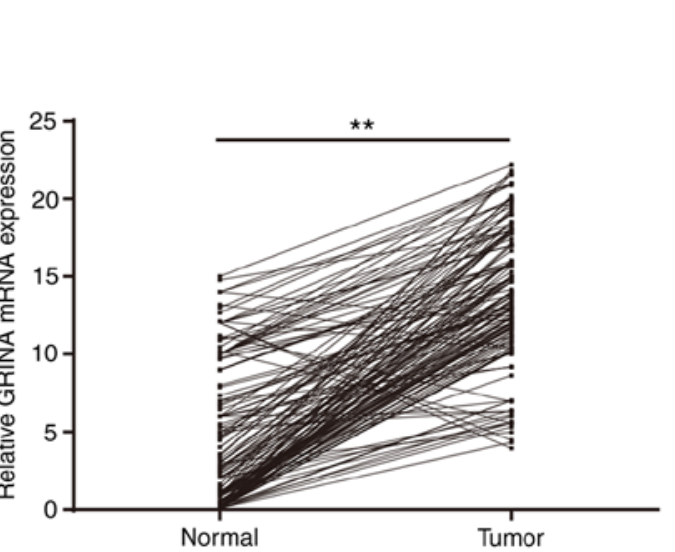

E
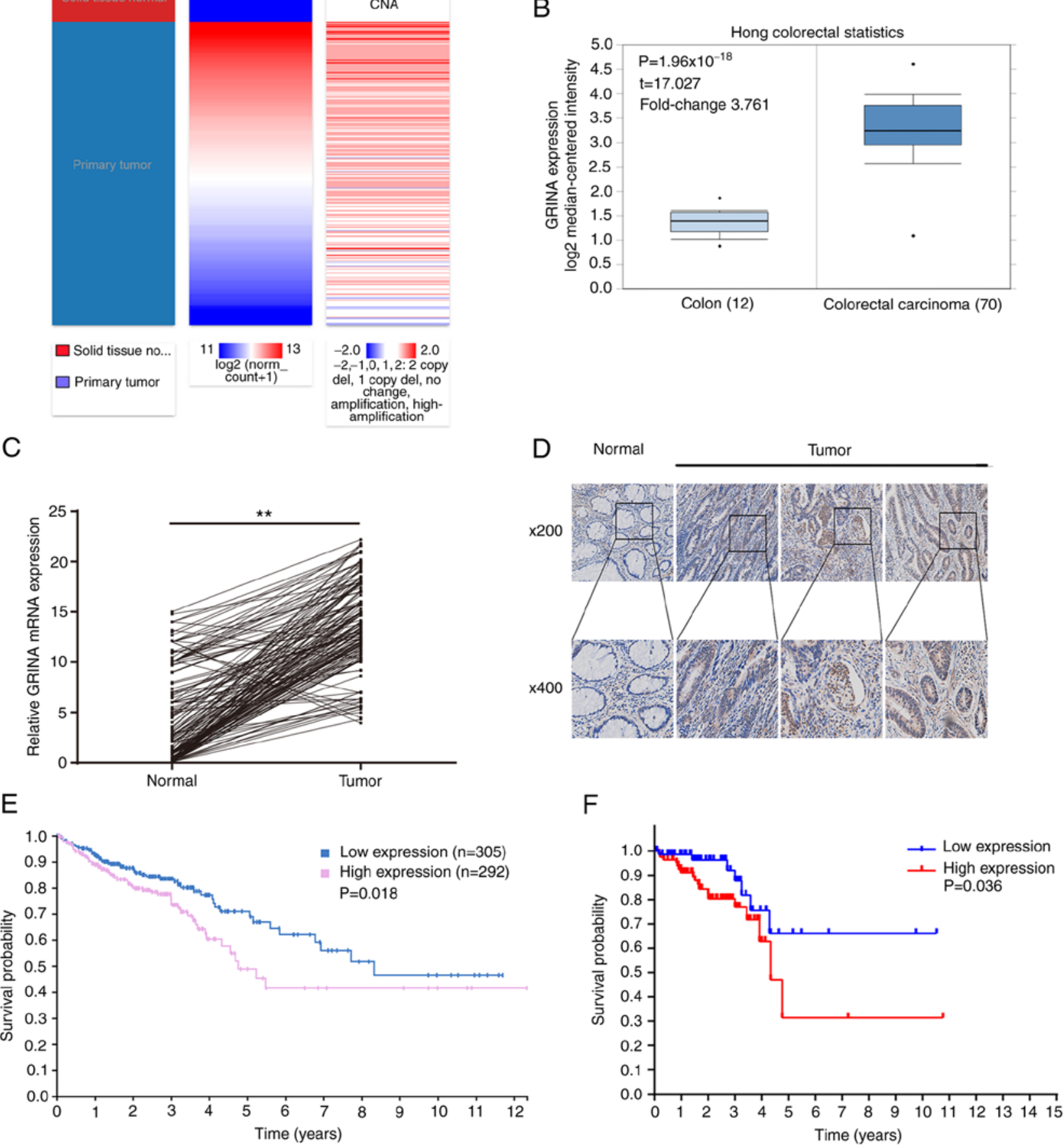

Figure 2. GRINA expression is upregulated in CRC samples. (A) Heatmap of GRINA mRNA expression and CNAs in CRC cases obtained from TCGA. (B) Box plots based on the Oncomine-derived gene expression profiles. GRINA expression levels in the healthy (left plot) and CRC (right plot) samples were compared. (C) GRINA mRNA expression in 161 paired freshly obtained CRC samples. (D) Immunohistochemistry analysis of GRINA protein expression levels in 161 CRC samples. (E) Survival curve of patients with CRC based on GRINA expression obtained from THPA. (F) Kaplan-Meier survival curves of the recruited cohort of patients with CRC based on GRINA mRNA expression levels. ${ }^{* *} \mathrm{P}<0.01$ vs. healthy. GRINA, glutamate receptor, ionotropic, $\mathrm{N}$-methyl D-aspartate-associated protein 1; CRC, colorectal cancer; CNA, copy number alterations; TCGA, The Cancer Genome Atlas; THPA, The Human Protein Atlas.

miR-296-3p in CRC cell proliferation, migration and invasion, a pcDNA3.1-GRINA overexpression plasmid with no 3'-UTR or an empty vector was transfected into LoVo cells with or without ectopic expression of miR-296-3p in a rescue assay. GRINA relative mRNA and protein expression levels were increased by transfecting LoVo cells with pcDNA3.1-GRINA plasmid compared with its expression in the NC plasmid group (Fig. S1). As shown in Fig. 6A, the western blotting results verified that GRINA expression was increased following co-transfection with miR-296-3p mimics and pcDNA3.1-GRINA plasmid. Conforming to target protein expression, miR-296-3p mimics also significantly suppressed LoVo cell proliferation, migration and invasion compared with the miR-NC+NC plasmid group (Fig. 6B-D). 
Table I. Association between GRINA expression and clinicopathological parameters in 161 patients with colorectal cancer.

\begin{tabular}{|c|c|c|c|}
\hline \multirow[b]{2}{*}{$\begin{array}{l}\text { Clinicopathological } \\
\text { parameter }\end{array}$} & \multicolumn{2}{|c|}{ GRINA expression } & \multirow[b]{2}{*}{ P-value } \\
\hline & $\begin{array}{c}\text { Low } \\
(n=64)\end{array}$ & $\begin{array}{l}\text { High } \\
(n=97)\end{array}$ & \\
\hline Age & & & $0.045^{\mathrm{a}}$ \\
\hline$<60$ & 27 & 25 & \\
\hline$\geq 60$ & 37 & 72 & \\
\hline Sex & & & 0.675 \\
\hline Male & 30 & 50 & \\
\hline Female & 34 & 47 & \\
\hline T stage & & & 0.775 \\
\hline $\mathrm{T} 1$ and $\mathrm{T} 2$ & 22 & 30 & \\
\hline $\mathrm{T} 3$ and $\mathrm{T} 4$ & 42 & 67 & \\
\hline Lymphatic invasion & & & $<0.001^{\mathrm{b}}$ \\
\hline Absent & 43 & 34 & \\
\hline present & 21 & 63 & \\
\hline TNM stage & & & $0.011^{\mathrm{a}}$ \\
\hline I & 17 & 10 & \\
\hline II & 20 & 27 & \\
\hline III & 27 & 60 & \\
\hline Differentiation & & & 0.058 \\
\hline Well & 20 & 15 & \\
\hline Moderate & 25 & 45 & \\
\hline Poor & 19 & 37 & \\
\hline Tumor location & & & 0.632 \\
\hline Colon & 31 & 42 & \\
\hline Rectum & 33 & 55 & \\
\hline
\end{tabular}

${ }^{\mathrm{a}} \mathrm{P}<0.05$ and ${ }^{\mathrm{b}} \mathrm{P}<0.01$. GRINA, glutamate receptor, ionotropic, $\mathrm{N}$-methyl D-aspartate-associated protein 1.

Compared with the control cells, GRINA-overexpression LoVo cells displayed significantly increased proliferation, migration and invasion (Fig. 6B-D). Moreover, simultaneous GRINA and miR-296-3p overexpression partially decreased miR-296-3p-mediated inhibition in LoVo cells (Fig. 6B-D). Therefore, the results confirmed that GRINA was a target of miR-296-3p.

\section{Discussion}

Aberrant NMDAR expression has been detected in several types of cancer, including oral squamous cell carcinoma (OSCC), cutaneous squamous cell carcinoma, prostate cancer and GC (17). NMDAR1 (a glutamate receptor) expression in cutaneous squamous cell carcinoma is significantly associated with cancer metastasis and differentiation (18). In OSCC, NMDAR1 upregulation is significantly associated with cancer stage, lymph node metastasis and tumor size (19). GRINA is a member of the NMDAR family that is also known as NMDARA1 (4). Xu et al (7) verified the upregulation GRINA in GC, where its expression was positively associated with T stage, $\mathrm{N}$ stage, distant metastasis, histological differentiation, blood vessel invasion and perineuronal invasion.

In the present study, data from several databases were used to analyze GRINA expression. GRINA expression was increased in CRC tissues compared with that in healthy tissues. In the recruited cohort, primary CRC samples displayed significantly upregulated expression of GRINA at both the mRNA and protein levels compared with the corresponding healthy samples. Furthermore, GRINA expression levels were associated with age, TNM stage and lymphatic invasion. Survival analysis demonstrated that upregulated GRINA expression was associated with worse OS in patients with CRC. These results were consistent with previous studies $(7,18,19)$. Collectively, these results highlighted the potential role of GRINA in the development and progression of CRC.

Subsequently, the biological effects of GRINA on CRC development were determined. GRINA expression levels were significantly increased in CRC cells compared with those in normal colonic cells. Additionally, GRINA overexpression increased CRC cell proliferation, migration and invasion. GRINA also promoted the growth and metastasis of xenograft tumors in nude mice. Similar results have been observed with other NMDARs in previous studies $(20,21)$. For example, an NMDAR antagonist suppressed cancer development by inhibiting the extracellular signal-mediated kinase signaling pathway (20). Moreover, NMDAR NR2A subunit enhanced human GC cell (MKN45) proliferation (21). These findings demonstrate that GRINA may serve as an important oncogene in the development of CRC. SW480 tumorigenesis might be attributed to the APC and p53 signaling pathway, whereas LoVo cells possess wild-type p53 and their tumorigenesis might be attributed to the microsatellite instability phenomenon $(22,23)$. CRC cell lines were selected for the overexpression (SW480) and knock down (LoVo) experiments based on the endogenous expression of GRINA in these cells. The experiments performed using these cells provided consistent results that supported the hypothesis that GRINA promoted CRC development and progression. However, whether the characteristics of these two cells lines affects the specific mechanism of action of GRINA requires further investigation.

Subsequently, the molecular mechanisms underlying the effects of GRINA on mediating CRC progression were examined. First, the mechanism underlying the upregulated expression of GRINA in CRC was examined. GRINA is located on chromosome 8q24.3 (4), where the CNA is the leading cause of tumorigenesis in GC (24). By examining the CNAs in TCGA-CRC, the results demonstrated that primary CRC samples displayed GRINA amplification. Furthermore, upregulated GRINA mRNA expression was associated with amplification. Additionally, it was shown that GRINA was regulated by miR-296-3p. miR-296 is located on chromosome 20 q13.32 and serves a tumor suppressive role in pancreatic and cervical cancer via regulating certain targets $(25,26)$. miR-296-5p targets S100 calcium binding protein A4 to suppress CRC metastasis and epithelial-mesenchymal transition (15). Additionally, it was reported that miR-296-5p suppresses cell growth and promotes apoptosis in CRC cells via targeting arrestin b1-regulated activation of AKT (16). 


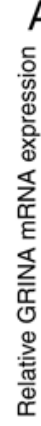

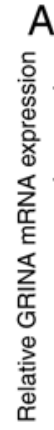

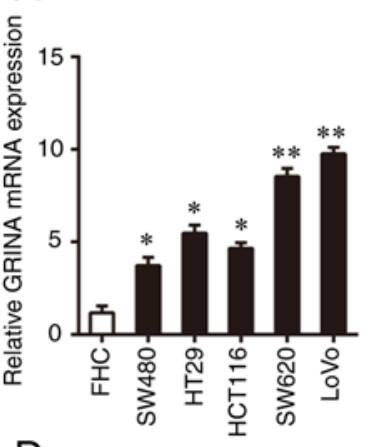

D

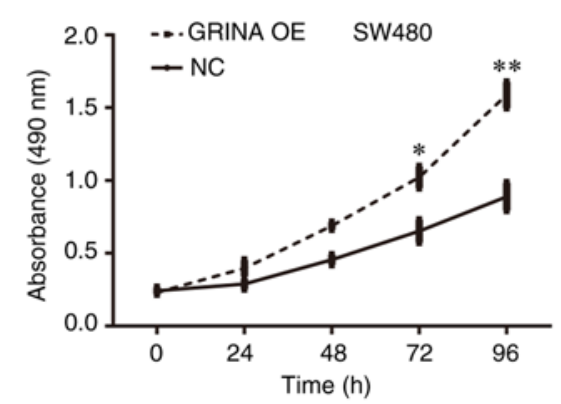

$\mathrm{F}$

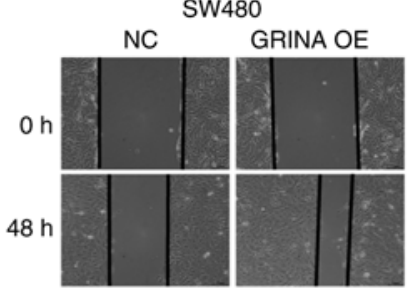

$\mathrm{H}$

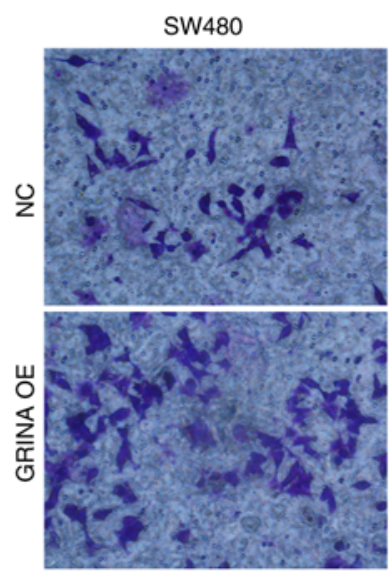

B

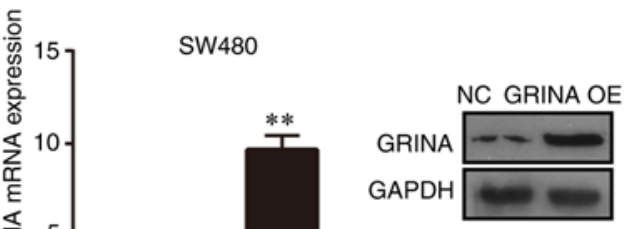

C

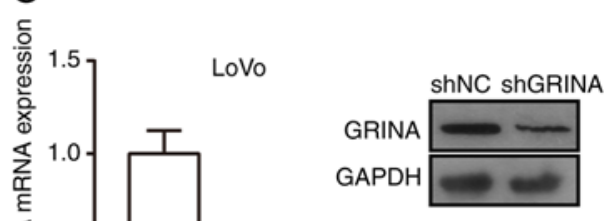

$\mathrm{E}$

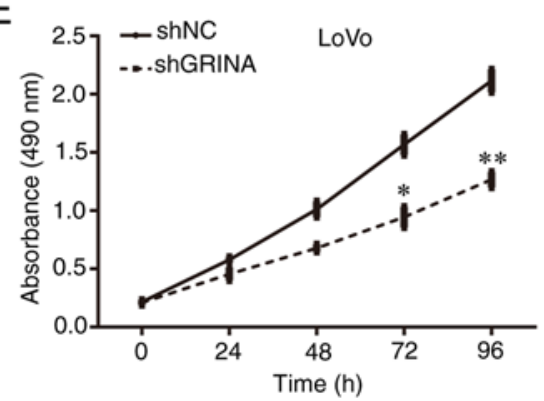

G
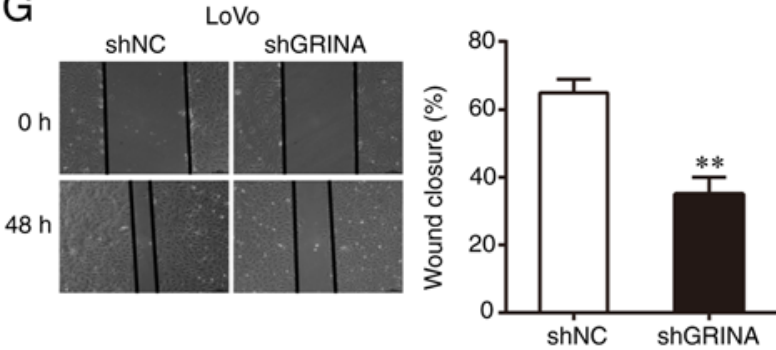

I
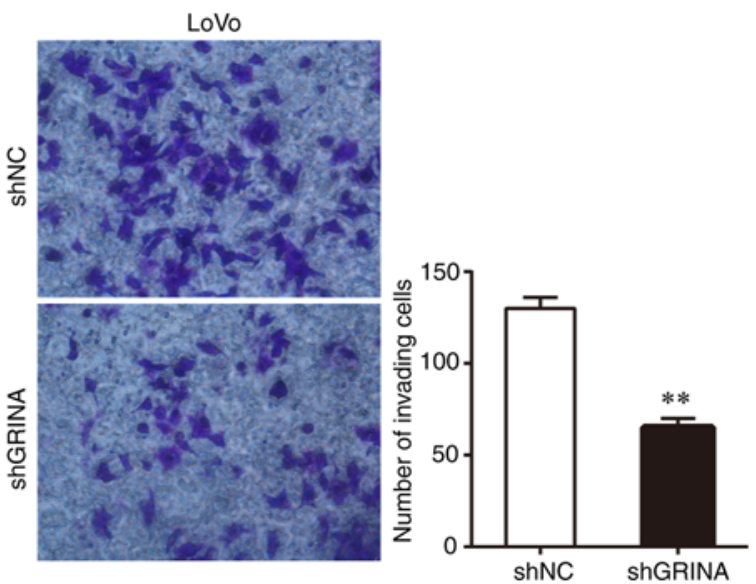

Figure 3. GRINA enhances CRC cell growth, invasion and migration in vitro. (A) Relative GRINA mRNA expression levels in the normal colonic epithelial cell line (FHC) and the five CRC cell lines (HCT116, HT29, LoVo, SW480 and SW620). (B) Following GRINA overexpression, GRINA mRNA and protein expression levels in SW480 were detected by performing RT-qPCR and western blotting. (C) Following GRINA knockdown, GRINA mRNA and protein expression levels in LoVo cells were detected by performing RT-qPCR and western blotting. Cell proliferation of (D) GRINA-overexpression SW480 and (E) GRINA-knockdown LoVo cells was detected by performing MTT assays. Cell migration of (F) GRINA-overexpression SW480 and (G) GRINA-knockdown LoVo cells was detected by performing wound healing assays. Cell invasion of (H) GRINA-overexpression SW480 and (I) GRINA-knockdown LoVo cells was detected by performing Transwell invasion assays. ${ }^{*} \mathrm{P}<0.05$ and ${ }^{* *} \mathrm{P}<0.01$. GRINA, glutamate receptor, ionotropic, N-methyl $\mathrm{D}$-aspartate-associated protein 1 ; CRC, colorectal cancer; RT-qPCR, reverse transcription-quantitative PCR; NC, negative control; OE, overexpression; sh, short hairpin RNA.

miR-296-3p may be derived the from the pre-miR-296 $3^{\prime}$ arm (27). Consistent with previous studies, the present study indicated that miR-296-3p may serve as a tumor suppressor gene in CRC. However, further investigations are required to verify the results of the present study
In the present study, luciferase reporter assays were used to validate GRINA as a direct target of miR-296-3p. miR-296-3p knockdown increased the expression levels of GRINA at the mRNA and protein levels in CRC cells, whereas miR-296-3p overexpression displayed the opposite 


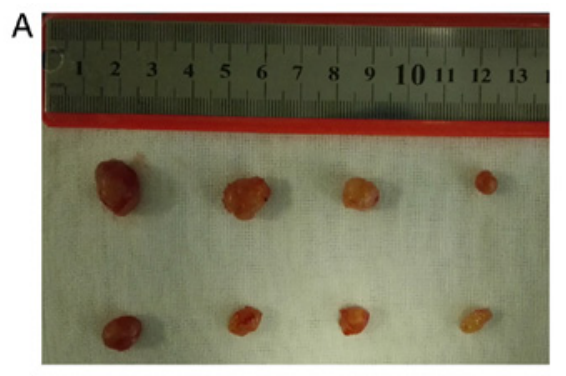

B

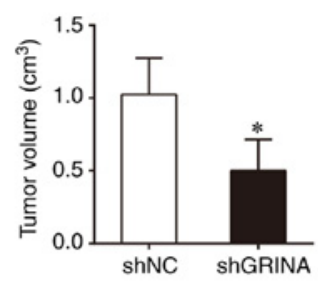

E
C

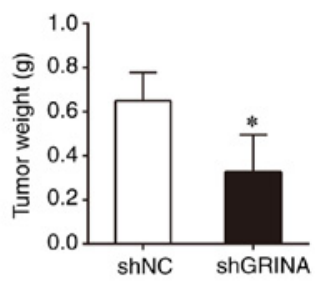

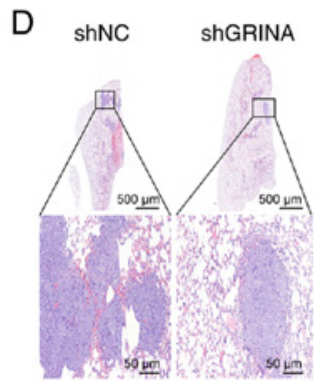

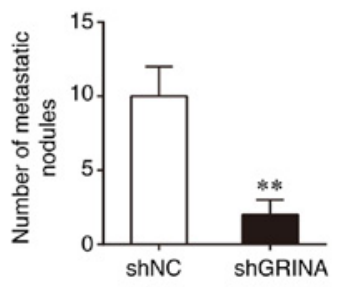

Figure 4. GRINA knockdown reduces LoVo cell proliferation and metastasis in vivo. (A) Representative image of xenograft tumors. Xenograft tumor (B) volume and (C) weight. (D) Representative hematoxylin and eosin staining images showing lung metastases in mice injected with shNC- or shGRINA-transfected LoVo cells via the tail vein. (E) Microscope determination of lung metastatic nodule numbers in each mouse. ${ }^{*} \mathrm{P}<0.05$ and ${ }^{* *} \mathrm{P}<0.01 \mathrm{vs}$. shNC. GRINA, glutamate receptor, ionotropic, N-methyl D-aspartate-associated protein 1; NC, negative control; sh, short hairpin RNA.

A

Position 133-139 of GRINA 3'UTR

WT 3' UTR

hsa-miR-296-3p

MUT 3 ' UTR

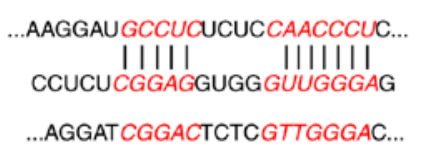

B

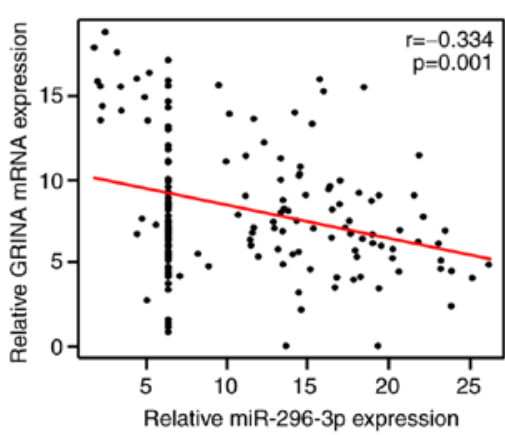

$\mathrm{F}$
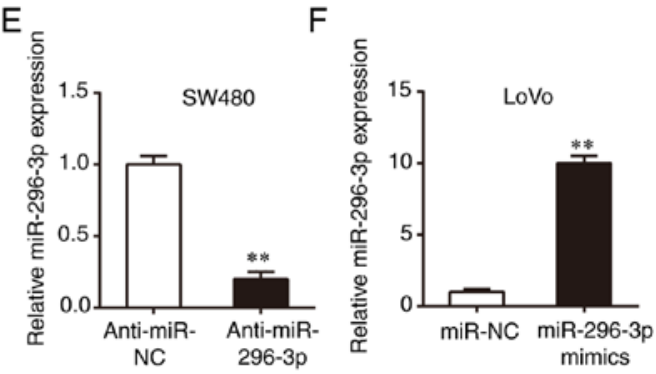

$\mathrm{H}$

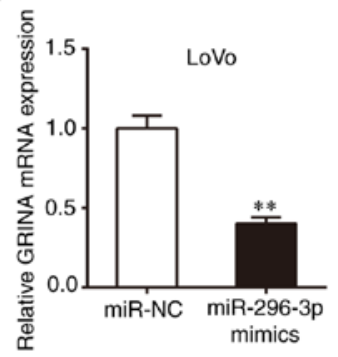

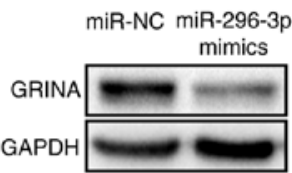

GAPDH

Anti-miR-

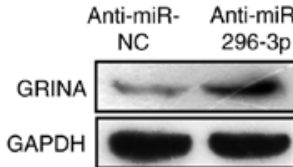

NC

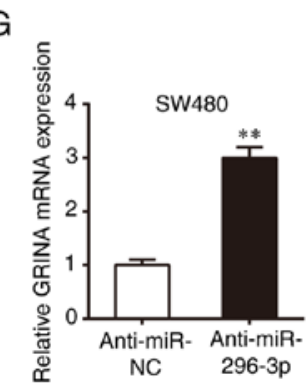

Figure 5. GRINA is a direct target of miR-296-3p. (A) WT and MUT putative target sequences of miR-296-3p in the 3'UTR of GRINA. (B) miR-296-3p expression was negatively correlated with GRINA expression in colorectal cancer samples. Luciferase activities of psicheck-2-GRINA 3'UTR MUT and WT vectors in 293T cells co-transfected with (C) miR-296-3p mimics, miR-NC, (D) anti-miR-296-3p or anti-miR-NC. miR-296-3p expression in (E) SW480 cells transfected with anti-miR-296-3p or anti-miR-NC and (F) LoVo cells transfected with miR-296-3p mimics or miR-NC. GRINA mRNA and protein expression levels in transfected (G) SW480 and (H) LoVo cell lines. ${ }^{~ P}<0.05$ and ${ }^{* *} \mathrm{P}<0.01$ vs. miR-NC or anti-miR-NC. GRINA, glutamate receptor, ionotropic, N-methyl D-aspartate-associated protein 1; WT, wild-type; MUT, mutant-type; UTR, untranslated region; miR, microRNA; NC, negative control. 
A

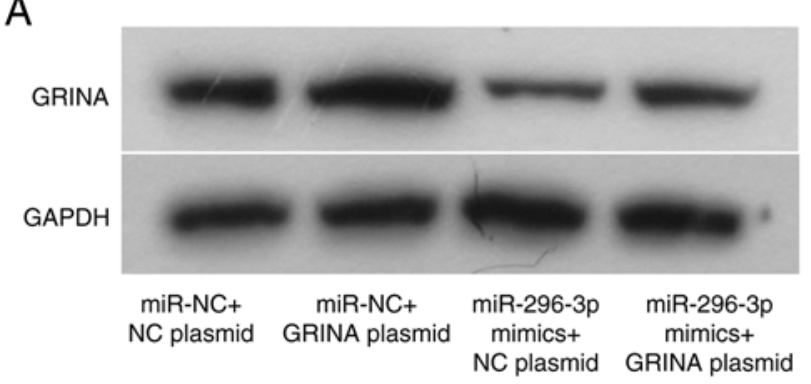

C

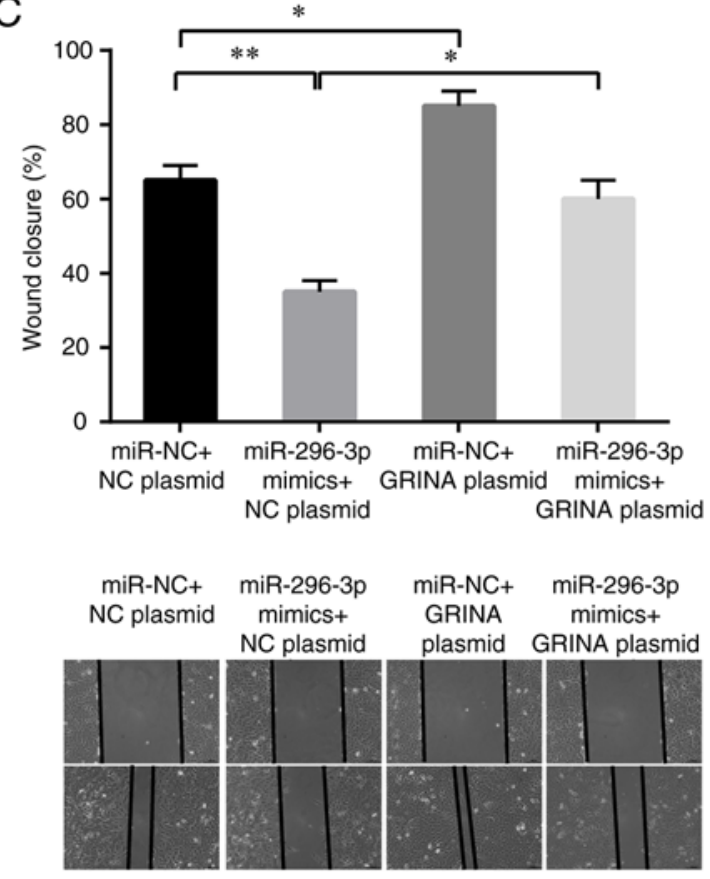

B

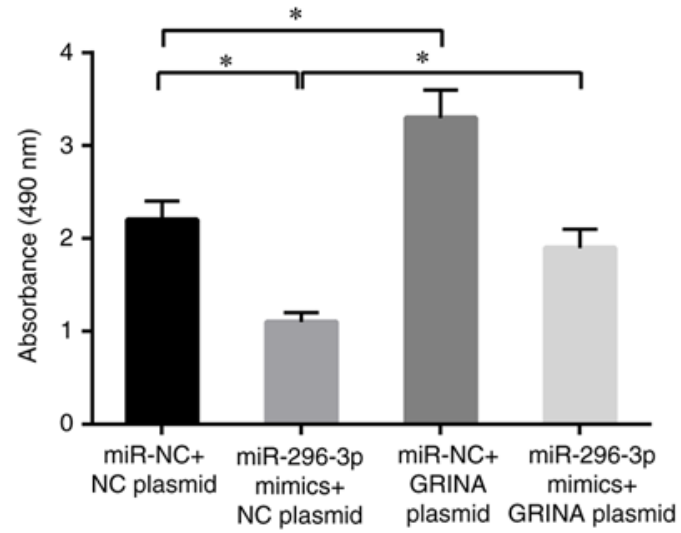

D

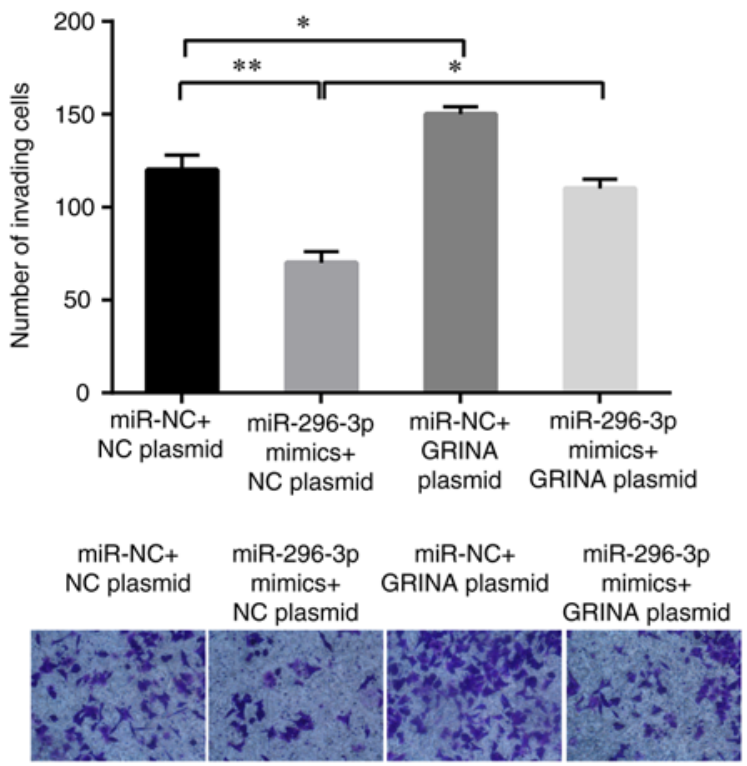

Figure 6. GRINA expression affects miR-296-3p expression levels in LoVo cells. (A) GRINA protein expression in LoVo cells transfected with GRINA overexpression vector and miR-296-3p mimics was detected using western blotting. (B) MTT assay was performed to assess cell proliferation after $96 \mathrm{~h}$. (C) Wound healing assay was performed to determine cell migration. (D) Transwell invasion assay was performed to determine cell invasion. "P<0.05 and ${ }^{* *} \mathrm{P}<0.01$. GRINA, glutamate receptor, ionotropic, $\mathrm{N}$-methyl D-aspartate-associated protein 1; miR, microRNA; NC, negative control.

effects. Additionally, miR-296-3p expression levels were negatively correlated with GRINA expression in the human CRC samples, and GRINA overexpression partially abrogated miR-296-3p-mediated inhibitory effects on CRC cells. Ma et al (28) reported that GRINA increases rectal cancer cell proliferation, invasion and migration, which may be regulated by miR-296-5p, which was consistent with the results of the present study.

In conclusion, the present study demonstrated that GRINA significantly increased CRC cell proliferation, invasion and migration via miR-296-3p. These results may improve the current understanding of the molecular mechanisms underlying the progression and metastasis of CRC and highlight potentially novel therapeutic targets for CRC. The miR-296-3p/GRINA axis should be further investigated as a candidate therapeutic target in anti-metastasis treatments for CRC. To the best of our knowledge, there are currently no data on the use of NMDA/GRINA inhibitors for CRC therapy, thus future studies should investigate this further.

\section{Acknowledgements}

Not applicable.

\section{Funding}

The present work was supported by the Sichuan Youth Science and Technology Foundation (grant no. 2017JQ0039), the Scientific and Technological Cooperation Project of Nanchong City (grant no. 18SXHZ0577), the Key Scientific Project of The Affiliated Hospital of North Sichuan Medical College (grant no. 19ZD004) and the Key Scientific Project of Sichuan health and Health Committee (grant no. 19ZD005).

\section{Availability of data and materials}

The datasets used and/or analyzed during the current study are available from the corresponding author on reasonable request. 


\section{Authors' contributions}

ZY, PL and YX designed the study, analyzed and interpreted the data, and wrote the manuscript. HT analyzed and interpreted the data. TZ and GZ analyzed and interpreted the data and wrote the manuscript. All authors read and approved the final manuscript. TZ and GZ confirm the authenticity of all the raw data.

\section{Ethics approval and consent to participate}

The present study was approved by the Medical Ethics Committee of North Sichuan Medical College [approval no. 2021ER(A)006]. All patients provided written informed consent for participation in the present study. The animal experiments were approved by the Experimental Animal Ethics Committee of North Sichuan Medical College (approval no. 20190907).

\section{Patient consent for publication}

Not applicable.

\section{Competing interests}

The authors declare that they have no competing interests.

\section{References}

1. Troiani T, Zappavigna S, Martinelli E, Addeo SR, Stiuso P, Ciardiello F and Caraglia M: Optimizing treatment of metastatic colorectal cancer patients with anti-EGFR antibodies: Overcoming the mechanisms of cancer cell resistance. Expert Opin Biol Ther 13: 241-255, 2013.

2. Siegel RL, Miller KD and Jemal A: Cancer statistics, 2017. CA Cancer J Clin 67: 7-30, 2017.

3. Chen W, Zheng R, Baade PD, Zhang S, Zeng H, Bray F, Jemal A, Yu XQ and He J: Cancer statistics in China, 2015. CA Cancer J Clin 66: 115-132, 2016.

4. Collins C, Duff C, Duncan AM, Planells-Case R, Sun W, Norremolle A, Michaelis E, Montal M, Worton R and Hayden MR: Mapping of the human NMDA receptor subunit (NMDAR1) and the proposed NMDA receptor glutamate-binding subunit (NMDARA1) to chromosomes 9q34.3 and chromosome 8, respectively. Genomics 17: 237-239, 1993.

5. North WG, Gao G, Memoli VA, Pang RH and Lynch L: Breast cancer expresses functional NMDA receptors. Breast Cancer Res Treat 122: 307-314, 2010.

6. North W, Liu F, Tian R, Abbasi H and Akerman B: NMDA receptors are expressed in human ovarian cancer tissues and human ovarian cancer cell lines. Clin Pharmacol 7: 111-117, 2015.

7. Xu DH, Li Q, Hu H, Ni B, Liu X, Huang C, Zizhen ZZ and Zhao G: Transmembrane protein GRINA modulates aerobic glycolysis and promotes tumor progression in gastric cancer. J Exp Clin Cancer Res 37: 308, 2018.

8. Gehlenborg N, Noble MS, Getz G, Chin L and Park PJ: Nozzle: A report generation toolkit for data analysis pipelines. Bioinformatics 29: 1089-1091, 2013.

9. Goldman MJ, Craft B, Hastie M, Repečka K, McDade F, Kamath A, Banerjee A, Luo Y, Rogers D, Brooks AN, et al: Visualizing and interpreting cancer genomics data via the xena platform. Nat Biotechnol 38: 675-678, 2020.

10. Rhodes DR, Yu J, Shanker K, Deshpande N, Varambally R, Ghosh D, Barrette T, Pandey A and Chinnaiyan AM: ONCOMINE: A cancer microarray database and integrated data-mining platform. Neoplasia 6: 1-6, 2004.
11. Uhlén M, Fagerberg L, Hallström BM, Lindskog C, Oksvold P, Mardinoglu A, Sivertsson Å, Kampf C, Sjöstedt E, Asplund A, et al: Proteomics. Tissue-based map of the human proteome. Science 347: 1260419, 2015.

12. Fan XJ, Wan XB, Yang ZL, Fu XH, Huang Y, Chen DK, Song SX, Liu Q, Xiao HY, Wang L and Wang JP: Nail promotes lymph node metastasis and twist enhances tumor deposit formation through epithelial-mesenchymal transition in colorectal cancer. Hum Pathol 44: 173-180, 2013.

13. Livak KJ and Schmittgen TD: Analysis of relative gene expression data using real-time quantitative PCR and the 2(-Delta Delta C(T)) method. Methods 25: 402-408, 2001.

14. Xuan Y, Yang H, Zhao L, Lau WB, Lau B, Ren N, Hu Y, Yi T, Zhao X, Zhou S and Wei Y: MicroRNAs in colorectal cancer: Small molecules with big functions. Cancer Lett 360: 89-105, 2015.

15. He Z, Yu L, Luo S, Li M, Li J, Li Q, Sun Y and Wang C: miR-296 inhibits the metastasis and epithelial-mesenchymal transition of colorectal cancer by targeting S100A4. BMC Cancer 17: 140, 2017.

16. Zhang Z, Zhong X, Xiao Y and Chen C: MicroRNA-296 inhibits colorectal cancer cell grow th and enhances apoptosis by targeting ARRB1-mediated AKT activation. Oncol Rep 41: 619-629, 2018.

17. Kalariti N, Pissimissis $\mathrm{N}$ and Koutsilieris M: The glutamatergic system outside the CNS and in cancer biology. Expert Opin Investig Drugs 14: 1487-1496, 2005.

18. Kang M, Cho JH, Koo JK, Noh SU, Kim MY, Kang H, Oh ST, Kim HO and Park YM: The expression of NMDA receptor 1 correlates with clinicopathological parameters in cutaneous squamous cell carcinoma. Ann Dermatol 21: 382-388, 2009.

19. Choi SW, Park SY, Hong SP, Pai H, Choi JY and Kim SG: The expression of NMDA receptor 1 is associated with clinicopathological parameters and prognosis in the oral squamous cell carcinoma. J Oral Pathol Med 33: 533-537, 2004.

20. Stepulak A, Sifringer M, Rzeski W, Endesfelder S, Gratopp A Pohl EE, Bittigau P, Felderhoff-Mueser U, Kaindl AM, Bührer C, et al: NMDA antagonist inhibits the extracellular signal-regulated kinase pathway and suppresses cancer growth. Proc Natl Acad USA 102: 15605-15610, 2005.

21. Watanabe K, Kanno T, Oshima T, Miwa H, Tashiro C and Nishizaki T: The NMDA receptor NR2A subunit regulates proliferation of MKN45 human gastric cancer cells. Biochem Biophys Res Commun 367: 487-490, 2008.

22. Rochette PJ, Bastien N, Lavoie J, Guérin SL and Drouin R: SW480, a p53 double-mutant cell line retains proficiency for some p53 functions. J Mol Biol 352: 44-57, 2005.

23. Bras-Gonçalves RA, Rosty C, Laurent-Puig P, Soulié P, Dutrillaux B and Poupon MF: Sensitivity to CPT-11 of xenografted human colorectal cancers as a function of microsatellite instability and p53 status. Br J Cancer 82: 913-923, 2000.

24. Song K, Kim RN, Jeon S, Kim HI, Choi YL and Shin YK: Abstract 5171: An integrated analysis of copy number alteration and global gene expression reveals potential oncogenes underlying stomach cancer. Cancer Res 74: 5171, 2014.

25. Lv L and Wang X: MicroRNA-296 targets specificity protein 1 to suppress cell proliferation and invasion in cervical cancer. Oncol Res 26: 775-783, 2017.

26. Li H, Li J, Shi B and Chen F: MicroRNA-296 targets AKT2 in pancreatic cancer and functions as a potential tumor suppressor. Mol Med Rep 16: 466-472, 2017.

27. Li H, Ouyang XP, Jiang T, Zheng XL, He PP and Zhao GJ: MicroRNA-296: A promising target in the pathogenesis of atherosclerosis? Mol Med 24: 12, 2018.

28. Ma H, Zhang X, Li N, Lu X, Wei Y, Yuan N, Tian G and Li S: Glutamate receptor, ionotropic, N-methyl D-aspartate-associated protein 1, a potential target of miR-296, facilitates proliferation and migration of rectal cancer cells. Biosci Biotech Bioch 84: 2077-2084, 2020.

(i) $\ominus$ This work is licensed under a Creative Commons Attribution-NonCommercial-NoDerivatives 4.0 International (CC BY-NC-ND 4.0) License. 